\title{
Energy Storage Application Technology and Operation Model on the Customer Side in China and Abroad
}

\author{
Shi Zhiyong ${ }^{1}$, Wang Caixia ${ }^{1}$, Chen Ning ${ }^{1}$, Yuan Wei ${ }^{1}$, Ye Xiaoning ${ }^{1}$, and Li Qinmiao ${ }^{1}$ \\ ${ }^{1}$ State Grid Energy Research Institute CO., LTD., Beijing 102209, China
}

\begin{abstract}
As a superior flexible resource in a new power system with new energy as the main body, customer-side energy storage has great potential for future development. It expounds the application technology and operation model of customer-side energy storage in the United States and Germany, analyzes the operation model of china's customer-side energy storage and calculates internal rates of return of general commercial and industrial customers with a unitary tariff and large industrial customers with two-part tariff, and puts forward suggestions to promote the development of china's customer-side energy storage.
\end{abstract}

\section{Introduction}

Energy storage is an important technology and basic equipment to support a new power system. It is of great significance for promoting the green transformation of energy, ensuring energy security, and achieving carbon peak and carbon neutrality [1-2]. According to different energy storage configuration scenarios, it can be divided into power side, grid side and customer side energy storage. The customer side energy storage is mainly the energy storage configured after the customer meter, which is usually built on the customer's internal site or nearby, and connected to the customer's internal Distribution network [3]. China's electrochemical energy storage is mainly used on the customer side, with an installed capacity of $918 \mathrm{MW}$, accounting for $49 \%$. This article introduces foreign customer-side energy storage application technologies and business models, analyzes china's customer-side energy storage operation model and conducts profitability calculations, and proposes to promote the development of china's customer-side energy storage.

\section{Foreign customer-side energy storage operation model}

\subsection{United States}

In the United States, Front of the Meter (FTM) and Behind the Meter (BTM) are generally used to distinguish energy storage. The American Energy Storage Association defines that front of the meter is mainly connected to the transmission and distribution network or power generation. Assets can independently participate in the wholesale market [4]; after the table is mainly calculated by commercial, industrial or residential customers, it mainly participates in retail transactions. The role of energy storage on the client side mainly includes Back Power, increasing PV Self-Consumption, Demand Charge Reduction, and Time-of-Use Bill Management [5].

For residential customers, the main consideration is to reduce the cost of time-of-use electricity, while for commercial and industry customers (C\&I), reducing demand costs is an important reason for considering the installation of energy storage settings. Because customer demand is often calculated based on a certain period of time such as 15 or 30 minutes of load conditions, it is closely related to the peak load of the customer, and the peak load time of the customer is generally short. The application of energy storage equipment to reduce the peak load can effectively reduce the customer demand, thereby save customers' electricity bills.

Thanks to the influence of the Self-Generation Incentive Program (SGIP) policy, California has become the fastest growing region for customer-side energy storage in the United States. The SGIP policy was formulated in 2001 to reduce the peak load of the system, mainly for distributed power generation subsidies, and does not include energy storage; energy storage equipment used in conjunction with renewable energy was included in the subsidy in 2008; in 2009, to reduce greenhouses Gas emissions have expanded the compensation object from distributed power generation to distributed energy. Since then, independent energy storage equipment has also begun to enjoy compensation. Since then, the SGIP plan increased the total subsidy budget and set a gradually reduced compensation amount in five stages. In addition, the investment tax credit (ITC) in the United States also promotes the development of energy storage.

\footnotetext{
*Corresponding author: 49817190@qq.com
} 


\subsection{Germany}

Germany is the world's largest residential energy storage market. By the end of 2020, the installed capacity of residential energy storage in Germany will be approximately $2.3 \mathrm{GWh}$. More than 300,000 battery energy storage systems have been installed in German homes. The average installed capacity in 2019 is about $8 \mathrm{kWh}$, and in 2020 it is about $8.5 \mathrm{kWh}$. Nearly $70 \%$ of German household solar photovoltaic power generation projects are equipped with battery energy storage systems. The factors driving the development of the domestic energy storage market in Germany include significantly reduced energy storage system costs (system prices have fallen by $40 \%$ in the past three years), declining photovoltaic feed-in tariff (FIT), high residential retail electricity prices, and a high proportion of renewable energy power generation, German Bank for Reconstruction and Development (KfW) household energy storage subsidies, etc.

The rapid development of domestic energy storage devices in Germany is due to its diversified business models that have activated the energy storage market:

- "Cash sale" model: In order to reduce the FIT and the retail price of electricity, customers are increasingly inclined to self-consumption instead of buying electricity from the grid. The use of solar power generation systems in conjunction with residential storage energy systems can help expand the share of self-consumption, while the average purchase cost is still lower than the cost of power supply from the grid. The German energy storage market is mainly driven by an early adopter segment, which is characterized by customers being able to tolerate an incomplete return-driven approach, but mainly for the installation of residential energy storage systems for nonprofit purposes, such as hope Increase the independence of public utilities or actively support Germany's energy transition.

- "Utilities game" model: By reducing the barriers to adoption, so as to increase convenience for customers, rather than just to save costs, this helps to expand the market scale of residential energy storage.

- "Aggregation and overlay" mode: Unlike the "utility game", many residential energy storage systems are now aggregated into large "virtual batteries." This enables energy storage providers to solve a variety of use cases and may obtain further revenue streams in addition to providing energy storage hardware and surplus power.

\section{Customer-side operation model and profitability analysis in china}

\subsection{Application technology of customer-side energy storage}

According to different customer types and needs, customer-side energy storage application technologies can be divided into three categories:

The first category is to implement peak shaving, demand response and demand management for traditional loads. Peak shaving and valley filling is suitable for customers who consume a lot of electricity during peak hours. It is currently the largest commercial application. It reduces electricity costs through "valley charging and peak discharge"; demand response is obtained by responding to grid dispatch, helping to change or shifting electricity load Revenue; demand management reduces demand electricity bills by reducing power consumption spikes.

The second category is to develop integrated solar storage and integrated storage applications for new energy applications [6]. For customers with existing or newly built photovoltaic systems, the integrated solar storage smoothes the fluctuations in photovoltaic output and reduces the impact on the grid; "saves for day and night", increases the proportion of photovoltaic power generation for self-use, minimizes the rate of abandonment, and promotes photovoltaic consumption. The integration of charging and storage is suitable for customers who have charging stations or charging facilities. It is a buffer of energy/power between charging facilities and the grid, reducing the impact of charging power on the grid, and reducing electricity costs in areas where there are peak and valley tariffs for charging electricity [7].

The third category is to improve the reliability of power supply, which is applied to uninterruptible power supply (UPS) and backup power supply for communication base stations. UPS is suitable for all kinds of customers who need uninterrupted power supply. The communication base station needs to be equipped with backup power supply to ensure the power consumption of critical loads. Lead-carbon batteries and lithium-ion batteries have now begun to enter this field. Compared with traditional lead-acid batteries, they have the advantages of high energy density, good discharge performance, and simple maintenance. Electrochemical energy storage can not only be used as a backup power source, but also can be used as energy storage to carry out peak shaving and valley filling and participate in demand response, but the management system requires high, and the current cost is high.

\subsection{Customer-side energy storage operation model and profitability}

Customer-side energy storage mainly uses marketoriented methods to perform functions such as peak shaving, demand management, backup power supply, and integrated operation of optical storage. Peak shaving and valley filling is currently the most widely used mode of energy storage on the customer side. It mainly achieves peak-to-valley arbitrage through low charging and high discharging or reducing demand for electricity bills to achieve profitability. Due to the differences in peak-tovalley electricity prices in various provinces, cities and regions, energy storage projects in different regions have different economics. Considering that general industrial and commercial customers only use peak-to-valley arbitrage as the main profit model, large industrial customers can use energy storage to reduce the maximum 
demand electricity cost while reducing the electricity cost through the peak-to-valley price difference.

Calculated based on the 16 provinces, cities or regions that implement peak-to-valley tariff policies in the operation area of the State Grid Corporation of China. There are two types of customers, one is general industrial and commercial customers with a single price of $1-10 \mathrm{kV}$ voltage level; the other is $1-10 \mathrm{kV}$ Two-part electricity tariff industrial customers with voltage levels. The energy storage system uses $10 \mathrm{MW} / 20 \mathrm{MWh}$ lithium iron phosphate batteries, which are calculated according to the charge and discharge once a day (365 times/year) and once during the working day (260 times/year).

(1) General commercial and industrial customers with a unitary tariff

If the energy storage system is charged and discharged once a day, the peak-to-valley price difference in Beijing is the largest, and the yield is the highest, reaching $22.2 \%$, followed by Jiangsu, Henan, Gansu, and Shandong. The remaining provinces are difficult to achieve a yield of $8 \%$; if energy storage is only in when charging and discharging on a working day, only Beijing and Jiangsu have room for profit, and it is difficult for the remaining provinces to achieve an $8 \%$ yield.

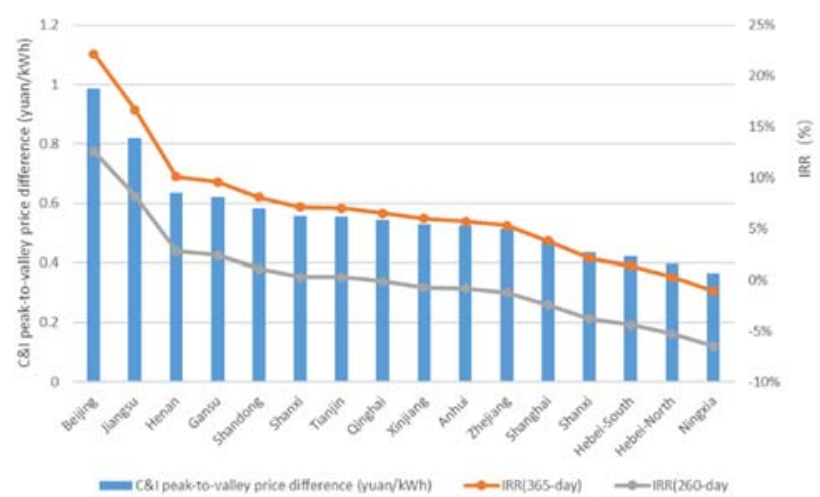

Figure 1. The relationship between the general commercial and industrial peak-to-valley price difference and the internal rate of return of energy storage

Table1. The relationship between the general commercial and industrial peak-to-valley price difference and the internal rate of return of energy storage

\begin{tabular}{|c|c|c|c|}
\hline Province & $\begin{array}{c}\text { C\&I peak-to-valley } \\
\text { price difference } \\
\text { (yuan/kWh) }\end{array}$ & $\begin{array}{c}\text { IRR(36 } \\
\text { 5-day) }\end{array}$ & $\begin{array}{c}\text { IRR(26 } \\
\text { 0-day }\end{array}$ \\
\hline Beijing & 0.9861 & $22.20 \%$ & $12.60 \%$ \\
\hline Jiangsu & 0.8206 & $16.70 \%$ & $8.20 \%$ \\
\hline Henan & 0.6356 & $10.10 \%$ & $2.80 \%$ \\
\hline Gansu & 0.6212 & $9.60 \%$ & $2.40 \%$ \\
\hline Shandong & 0.5818 & $8.10 \%$ & $1.10 \%$ \\
\hline Shanxi & 0.5574 & $7.10 \%$ & $0.30 \%$ \\
\hline Tianjin & 0.555 & $7.00 \%$ & $0.30 \%$ \\
\hline
\end{tabular}

\begin{tabular}{|c|c|c|c|}
\hline Qinghai & 0.5434 & $6.50 \%$ & $-0.10 \%$ \\
\hline Xinjiang & 0.5288 & $6.00 \%$ & $-0.70 \%$ \\
\hline Anhui & 0.5225 & $5.70 \%$ & $-0.80 \%$ \\
\hline Zhejiang & 0.512 & $5.30 \%$ & $-1.20 \%$ \\
\hline Shanghai & 0.477 & $3.80 \%$ & $-2.40 \%$ \\
\hline Shanxi & 0.4358 & $2.10 \%$ & $-3.80 \%$ \\
\hline $\begin{array}{c}\text { Hebei- } \\
\text { South }\end{array}$ & 0.4202 & $1.40 \%$ & $-4.40 \%$ \\
\hline $\begin{array}{c}\text { Hebei- } \\
\text { North }\end{array}$ & 0.3962 & $0.30 \%$ & $-5.30 \%$ \\
\hline \begin{tabular}{c} 
Ningxia \\
\hline
\end{tabular} & 0.3656 & $-1.10 \%$ & $-6.50 \%$ \\
\hline
\end{tabular}

(2) Large industrial customers with two-part tariff

The peak-to-valley price difference between large industrial customers is generally smaller than that of general industrial and commercial customers. When only considering the peak-to-valley price difference, if the energy storage system is charged and discharged once a day, the peak-to-valley price gap in Shanghai is the largest, with the highest yield, reaching $14.8 \%$, followed by Jiangsu, Shaanxi, and Shaanxi. Henan, Beijing, Shandong, and other provinces are difficult to achieve a yield rate of $8 \%$; if energy storage is only charged and discharged on a working day, no province has a yield rate of $8 \%$.

Under the two-part electricity price, customers need to pay the required electricity fee in addition to the cost of electricity per kilowatt-hour. For short-term peak electricity consumption every day, energy storage can reduce the demand for electricity costs, and the degree of reduction is determined by the length of energy storage discharge and the discharge power. Taking Shanghai as an example, the electricity demand fee is 40 yuan $/ \mathrm{kW} / \mathrm{month}$. If $10 \mathrm{MW}$ energy storage can reduce the demand of $5 \mathrm{MW}$, the electricity demand will be reduced by 2.4 million yuan every year. If the energy storage is only charged and discharged on working days, the comprehensive internal rate of return will be $19.8 \%$.

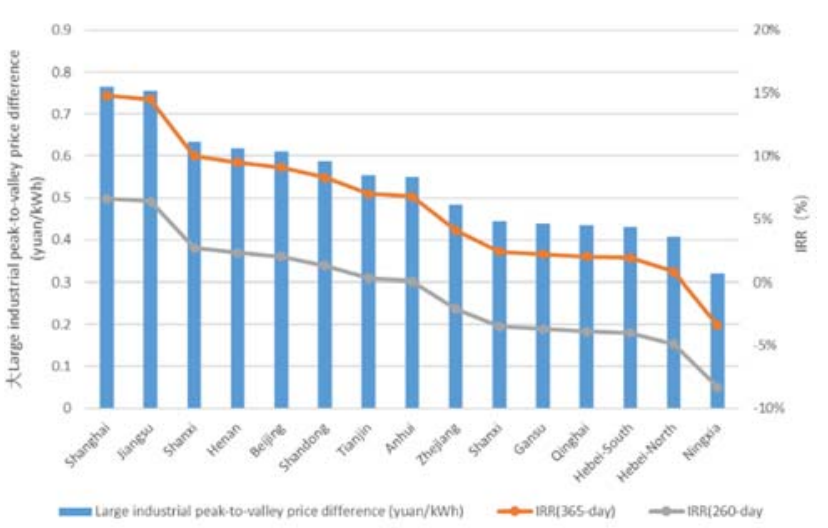

Figure 2. The relationship between the peak-to-valley price difference of large industrial customers and the internal rate of return of energy storage 
Table2. The relationship between the peak-to-valley price difference of large industrial customers and the internal rate of return of energy storage

\begin{tabular}{|c|c|c|c|}
\hline Province & $\begin{array}{c}\text { Large industrial } \\
\text { peak-to-valley price } \\
\text { difference } \\
(\text { yuan/kWh) } \\
\end{array}$ & $\begin{array}{c}\operatorname{IRR(36} \\
\text { 5-day) }\end{array}$ & $\begin{array}{c}\text { IRR(26 } \\
\text { 0-day }\end{array}$ \\
\hline Shanghai & 0.766 & $14.80 \%$ & $6.60 \%$ \\
\hline Jiangsu & 0.7558 & $14.50 \%$ & $6.40 \%$ \\
\hline Shanxi & 0.6334 & $10.00 \%$ & $2.70 \%$ \\
\hline Henan & 0.6189 & $9.50 \%$ & $2.30 \%$ \\
\hline Beijing & 0.6098 & $9.10 \%$ & $2.00 \%$ \\
\hline Shandong & 0.5881 & $8.30 \%$ & $1.30 \%$ \\
\hline Tianjin & 0.555 & $7.00 \%$ & $0.30 \%$ \\
\hline Anhui & 0.5502 & $6.80 \%$ & $0.10 \%$ \\
\hline Zhejiang & 0.484 & $4.10 \%$ & $-2.10 \%$ \\
\hline Shanxi & 0.4437 & $2.40 \%$ & $-3.50 \%$ \\
\hline Gansu & 0.4383 & $2.20 \%$ & $-3.70 \%$ \\
\hline Qinghai & 0.4342 & $2.00 \%$ & $-3.90 \%$ \\
\hline $\begin{array}{l}\text { Hebei- } \\
\text { South }\end{array}$ & 0.431 & $1.90 \%$ & $-4.00 \%$ \\
\hline $\begin{array}{l}\text { Hebei- } \\
\text { North }\end{array}$ & 0.4074 & $0.80 \%$ & $-4.90 \%$ \\
\hline Ningxia & 0.3198 & $-3.40 \%$ & $-8.30 \%$ \\
\hline
\end{tabular}

The conclusion shows that the profitability of customer-side energy storage is affected by two aspects. The first is the local peak-to-valley electricity price difference. The larger the electricity price difference, the higher the profit. However, the peak-to-valley electricity price policy is stronger, and energy storage arbitrage is a decades-long period. Cyclical investment behaviors have relatively high policy risks; second, the company's own operating conditions, energy storage peak and valley arbitrage requires a long-term stable load, especially for large industrial customers, which have relatively high operating risks. Therefore, energy storage peak-to-valley arbitrage is still concentrated in Beijing, Jiangsu and other industrial parks or commercial premises with large peakto-valley price differences and relatively stable business operations.

\section{Conclusion and suggestion}

The rapid development of customer-side energy storage in the United States and Germany is driven by policies and electricity prices, and the application model is relatively flexible. China's customer-side energy storage is mainly limited to peak-to-valley arbitrage, which is greatly affected by peak-to-valley electricity prices. In order to promote the development of customer-side energy storage, the following suggestions are put forward: first, to promote the development of energy storage by widening the peak-to-valley price difference, reflecting the price of electricity supply and demand; second, vigorously promoting new models such as optical storage and optical storage charging; third, introducing related Policies to promote customer-side energy storage to participate in demand response and play multiple values.

\section{Acknowledgement}

This work is supported by the project of "Research on key technologies and value of multi-scenario large-scale customer-side energy storage applications based on ubiquitous power Internet of Things".

\section{References}

1. Chaoyang D, Junhua Z, Fushuan W and Yusheng X From smart grid to energy internet: Basic concept and research framework. Automation of Electric Power Systems,2014, 38(15), 1-11.

2. Chengshan W, Zhen W and Peng L Prospects and challenges of distributed electricity storage technology. Automation of Electric Power Systems,2014, 38(16), 1-8.

3. Zechun H, Huajie D, Yonghua S and Fang Z Research status and prospect of energy storage application under energy internet background. Electric Power Construction, 2016, 37(8), 8-17.

4. Xisheng T. Applications and marketing mode of energy storages in power system. Electric Power Construction, 2016, 37(8), 2-7.

5. Jianlin L, Huimeng M, Xiaodong Y, Zhan W and Le G Overview on key applied technologies of largescale distributed energy storage. Power System Technology, 2017, 41(10), 3365-75.

6. Bibin $\mathrm{H}$ and Qionghui L Value assessment for energy storage in supporting large-scale integration of distributed PVs. Electric Power Automation Equipment, 2016, 36(6), 88-93.

7. Shuanghui L Shengxia C and Shouxiang W Economy evaluation and development suggestions for distributed PV-energy storage system in china. Electric Power, 2016, 48(2), 139-144. 